\title{
Conversa com os editores
}

\author{
Victor Chaves de Souza \\ Etienne Alfred Higuet
}

O presente número contém um dossiê sobre os "Cem anos da Teologia da Cultura de Paul Tillich", em referência à conferência inaugural do nosso filósofo e teólogo na Sociedade Kantiana de Berlim em 1919. É o segundo dossiê que publicamos com o mesmo título, o primeiro tendo saído no número 2 de 2019. É que, em 2019 e 2020, não conseguimos organizar o $25^{\circ}$ Seminário em Diálogo com o pensamento de Paul Tillich sobre o mesmo tema, por diversos motivos, especialmente a pandemia em 2020. Então, os artigos que publicamos no dossiê deste número são o resultado de conferências e comunicações proferidas oralmente e virtualmente no evento virtual que aconteceu em 2021. Remetemos às notícias, para maiores detalhes sobre o evento. Depois do dossiê, o leitor encontrará ainda uma seção livre e uma resenha.

\section{Apresentação do dossiê}

Todos os textos se relacionam, de certo modo, com o tema do seminário, objeto da seguinte apresentação: Em 1919, por ocasião de uma conferência na Sociedade Kantiana de Berlim, Paul Tillich delineou em um texto o que viria a ser o programa de sua obra: Sobre a ideia de uma teologia da cultura (Über die Idee einer Theologie der Kultur). Precursora de uma compressão hermenêutica, secularizada e, a seu modo, "pública" da teologia, a proposta de Tillich alinhava-se ao pensamento crítico daquele contexto, cuja noção axial era a de história. No seu caso, contudo, os pressupostos filosóficos dos quais partia definiam cultura e religião indissociáveis - não por seus conteúdos, mas por suas funções na dinâmica elementar da vida social e cultural humana: a linguagem.

Uma das preocupações de Tillich era a de salvaguardar o conceito de religião por seu papel numa "ciência do Espírito" (Geisteswissenschaften). Para ele, era necessário afirmar a unidade da ação criativa, 
moral e cognitiva a partir de uma mesma e adequada base normativa, do contrário, reiterar-se-ia a fragmentação e dissolução da vida humana - preocupação que faz muito sentido se considerarmos que estamos no ano seguinte ao fim da Primeira Grande Guerra. Os esforços, portanto, desta crítica não apenas pretendiam melhor compreender o absurdo racionalizado e objetivado de uma guerra ímpar, masdefender o presente e conduzi-lo a um futuro possível.

Uma contribuição decisiva da teologia da cultura de Tillich, por sua vez, lança luz justamente aos limites de um futuro possível. Nada há de novo em relacionar a função normativa da religião com a ação cultural, o que Tillich denuncia como "heteronomia". A relação que Tillich propõe, portanto, se dá em sentido inverso: primeiro, ele esvazia a religião de seus conteúdos e a define funcionalmente a partir do conceito de incondicional. Disso decorre uma noção essencialmente crítico-negativa de religião: ela é a função orientadora ao que fundamenta e, ao mesmo tempo, impõe os limites (abismo) de toda ação cultural. Prometer e não cumprir suas promessas senão de forma ambígua, a partir dessa chave de análise, torna-se característica tanto da cultura quanto da religião.

(Pouco mais que) um século depois, a Sociedade Paul Tillich do Brasil, propõe-se tematizar a teologia da cultura de Tillich com a tarefa básica a qualquer tratamento crítico: reconhecer a relevância no quadro de seus limites. Os objetivos se definem em torno da proposta do seminário desde a suas primeiras edições, que é fomentar o diálogo com o pensamento deste autor e qualificar sua recepção crítica e criativa no contexto do estudo da religião no Brasil e em língua portuguesa em geral. Em particular, nos perguntamos pelo poder e limites heurísticos não apenas do quadro conceitual que a teologia da cultura representa, mas também de seus pressupostos, determinados, por um lado, pelo contexto e época do autor e, por outro lado, pelo nosso próprio contexto e espírito de época.

Praticamente todos os artigos do dossiê relacionam efetivamente o contexto da produção da Teologia da Cultura de Paul Tillich com o contexto atual. Os quatro primeiros trazem as conferências principais e as reações dos ouvintes. Iniciamos com a conferência de Fábio Henrique Abreu, proferida no dia 15/09/2021, com o título: „, denn der tragende Gehalt der Kultur ist die Religion und die notwendige Form 
der Religion ist die Kultur ". Considerações sobre os fundamentos teórico-conceituais e sistemáticos da teologia da cultura de Paul Tillich. A intenção era reconstruir a teologia da cultura de Paul Tillich de forma sistemática. A tese apresentada afirma que o modo da relação entre religião e cultura no programa teológico-cultural de Tillich é não apenas mediado por uma filosofia do espírito e do sentido, como também reivindica uma teoria dos símbolos plenamente delineada. A partir da elucidação de sua filosofia do espírito e do sentido, o conceito de religião, enquanto direcionamento ao incondicionado, é apresentado em sua natureza mais própria. Em seguida, uma análise da função do conceito de símbolo para uma delimitação mais precisa da teologia da cultura de Tillich é oferecida. É a partir do conceito de símbolo que a forma própria do relacionamento entre religião e cultura, i.e., entre o condicionado e o incondicionado, é articulada.

A segunda conferência foi proferida por Etienne Alfred Higuet no dia 20/09/2021, com o título: Saúde e salvação em Paul Tillich, na perspectiva da Teologia da Cultura - o caso da pandemia no Brasil. O texto é organizado segundo o esquema da Teologia Sistemática, da correlação entre situação (questões existenciais) e resposta (interpretação dos símbolos religiosos). Já que a correlação se produz sempre num contexto histórico-cultural, usa-se como referencial os principais conceitos da Teologia da Cultura de Paul Tillich, apresentados na introdução. Em seguida, explicita-se a situação cultural da pandemia no Brasil, centrando-se nas diversas dimensões da cultura da saúde, na situação econômica, nas atitudes negacionistas políticas e religiosas e nas críticas levantadas contra o negacionismo. A segunda parte apresenta algumas reflexões a partir da Teologia da Cultura: a aceitação como resposta ao negacionismo, o pensamento holista aplicado à saúde, o mito e a utopia da saúde universal. A conclusão coloca a questão de um novo Kairos.

A terceira conferência: Teologia, religião, cultura. Reflexões sobre a teologia sistemática seguindo Paul Tillich, foi apresentada por Christian Danz no dia 22/09/2021. O objetivo era esboçar as linhas básicas de uma teologia sistemática da cultura moderna na era do pluralismo religioso. $\mathrm{O}$ artigo começa com uma breve reconstrução dos fundamentos sistemáticos da teoria da cultura de Tillich a partir do 
esboço Rechtfertigung und Zweifel, de 1919. Em seguida, os problemas sistemáticos da teologia da cultura de Tillich, que dizem respeito principalmente ao seu conceito de religião, são discutidos. A fim de resolver essas dificuldades, propõe-se entender a religião como um evento de comunicação autorreferencial, autoconsciente e em si mesmo estruturado, bem como prescindir de um conceito geral de religião, como defende Tillich. Com base nisso, a terceira seção conclusiva do artigo elabora as características básicas de uma teologia sistemática da cultura que retoma a intenção de Tillich, conferindo-a não apenas uma justificativa diferente, como também uma direção distinta.

Os três artigos mencionados até agora trazem, em complemento, algumas reações às conferências. Sendo a reação de Fábio Henrique Abreu à conferência de Christian Danz mais comprida, ela constitui o quarto artigo da revista: Religião como um sistema autorreferencial de comunicação religiosa: uma avaliação com perguntas para um desafiante e novo sistema teológico. Notas de uma abordagem preliminar e (meramente) intuitiva. Segundo o autor, a palestra de Danz, intitulada "Theology, Religion, Culture. Reflections on the Task of Systematic Theology following Paul Tillich", traz não apenas uma exposição exegética da teologia da cultura de Tillich, como também críticas intensas no que diz respeito à fundamentação de seu conceito de religião em face do pluralismo religioso das sociedades democráticas modernas. A tese apresentada por Danz pode ser resumida em três pontos: 1) a fundamentação transcendental do conceito de religião de Tillich torna sua teologia incapaz de lidar com o pluralismo religioso; 2) tendo-se em vista que o conceito acadêmico de religião é um produto do "neoprotestantismo", o conceito de religião deve ser restrito à religião cristã; 3) por fim, a função do conceito de religião dentro do sistema teológico reside em sua capacidade de apreender conceitualmente e determinar o cristianismo como religião. Com base na crítica à fundamentação do conceito de religião desenvolvido por Tillich, Danz propõe um novo conceito de religião sob o prisma de um "sistema autorreferencial de comunicação religiosa". Constitutivo para o sistema autorreferencial de comunicação religiosa é o conceito de "verstehende Aneignung", ou "apropriação compreensiva", que, por sua vez, somente pode ocorrer dentro do sistema de comunicação religiosa. O texto de Abreu apresenta- 
-se como uma tentativa, ainda incipiente e intuitiva, de oferecer uma aproximação "em suspeição" no que diz respeito ao sistema teológico proposto por Danz. A primeira parte é destinada à uma síntese compreensiva do conteúdo substantivo da palestra proferida. Na segunda parte, tece-se considerações iniciais e questionamentos em relação aos fundamentos do novo sistema.

Os sete artigos seguintes resultam das comunicações que foram realizadas na programação do GT Paul Tillich, que integrava o VIII Congresso da Associação de Programas de Pós-graduação em Ciências da Religião e Teologia (Anptecre), nos dias 28-30/09/2021. O primeiro artigo: A visão da massa por Paul Tillich e Juan Luis Segundo, é da autoria de Eduardo Gross. Segundo o autor, a perspectiva de Paul Tillich a respeito do moderno fenômeno da massa como uma configuração humana pretende ser uma crítica da depreciação protestante e burguesa tradicional em relação a ele. Seu texto Masse und Geist, de 1922, possui, nesse sentido, uma relação com a sua teologia da cultura, reivindicando uma relação próxima da liderança popular com o espírito cultural da massa. Mas uma apreciação inocente do espírito da massa - cujos perigos se tornaram claramente exemplares após a queda da república de Weimar - deveria ser evitada. A crítica de Segundo ao comportamento de massa ajuda a enfatizar o valor da personalidade e a importância de processos culturais pedagógicos.

Em seguida, trazemos o artigo: Distopia e religião em perspectiva tillichiana, de Joe Marçal Gonçalves Santos. A distopia consolidou-se como gênero narrativo no decorrer do século XX tanto na literatura quanto no cinema a partir de uma pretensão crítica à modernidade. Em contraste com a tradição literária iniciada pelo humanista inglês Tomas Morus, em Utopia (1516), a narrativa distópica desloca a ideia de não-lugar implicado no neologismo utopia da referência espacial e a situa em um tempo futuro, no qual o potencial destrutivo do presente é efetivado dramaticamente. O que interessa ao autor é a recorrência do tema religioso nesse conjunto de obras, para o que se propõe delinear categorias analíticas em diálogo com a teologia da cultura.

$\mathrm{O}$ artigo de Odenício Junior Marques de Melo: Teologia e cultura: tensões em tempos pandêmicos II, tem por objetivo propor uma reflexão, em continuidade ao texto publicado no v. 19, n. 2 (2020) dessa 
mesma revista, sobre a teologia e cultura no pensamento de Tillich como recursos de interpretação da espiritualidade, ou sobre a dor espiritual no contexto da pandemia. A reflexão encontra-se dividida em duas partes: na primeira, será feita uma correlação entre o contexto teológico-filosófico na peste bubônica no século XIV, onde se tenta visualizar algumas situações em comum entre aquele período e o que enfrentamos hoje com a covid-19. Na segunda, serão abordados os cuidados com a dor espiritual, tanto na dimensão coletiva, quanto na dimensão individual, a partir da teologia de Tillich, tentando entender as questões do ser como ponto de partida para a pergunta sobre Deus em situações limite.

Victor Siqueira Santos oferece o texto: O mundo como sacramento: A sacramentologia de Paul Tillich como crítica a um mundo em desintegração. Segundo o autor, Paul Tillich é muito conhecido por sua capacidade de correlacionar as situações políticas, sociais e culturais que o cercavam e as respostas da tradição cristã. Este artigo visa expor brevemente as bases da sacramentologia tillichiana, que realçam fatores que contribuem para um suporte teórico da crítica do autor ao mundo moderno. Para Tillich, o elemento sacramental é imprescindível ao cristianismo. A sacramentologia constitui um elemento integrador que sempre aponta para o sentido último da natureza e da história. Partindo desse pressuposto, Tillich lançou um olhar crítico ao mundo moderno tal como vinha sendo construído pela sociedade burguesa, observando um mundo em desintegração ao qual o elemento sacramental se tornou importante componente crítico-construtivo.

Os dois artigos seguintes relacionam o pensamento de Tillich com a literatura. Viviane de Sousa Rocha, em As veredas, o sertão, a vida: a dinâmica da fé de Riobaldo a partir de Paul Tillich, procura fazer emergir aspectos da fé de Riobaldo, ou seja, como a fé aparece nesse personagem tão peculiar, tão ambíguo, paradoxal, um ser tão ímpar? A questão surgiu a partir da leitura do livro de João Guimarães Rosa e da leitura de Paul Tillich (1985) na Especialização em Ciências da Religião. O livro de Tillich, Dinâmica da Fé (1985) será referência teórica, utilizado para refletir e estudar a fé. Assim, a partir dessa leitura, busca-se identificar a fé do personagem Riobaldo na narrativa de Grande Sertão: Veredas. Os objetivos específicos consistem em analisar 
a partir da definição de fé elaborada por Paul Tillich (1985), aspectos religiosos e relações com o sagrado e o transcendente presentes na fé do místico e filósofo Riobaldo. Busca-se aprofundar a leitura da obra, com alguns autores e pesquisadores, tais como Antonio Candido e Walnice Galvão. A questão que moveu a autora durante a pesquisa consiste na existência da fé em meio à dúvida.

$\mathrm{O}$ artigo de Ivanilton Aragão de Moura tem como título: Angústia e coragem de desespero na literatura modernista de Fernando Pessoa. Em A Coragem de Ser (1952), Tillich define o conceito de coragem como o ato de autoafirmação do ser diante da ameaça do não-ser. Ele percebia também na arte existencialista do século XX expressões da angústia da insignificação, resultando no desespero enquanto tentativa de incorporar tal angústia à coragem de ser como si próprio. A consciência da finitude que alimenta a angústia leva ao desespero em face da inevitável vitória do não-ser materializada na morte. A discussão aqui se dirige ao questionamento da literatura modernista a partir da obra de Fernando Pessoa. Ao compreender o humano do século XX como alguém que perdeu o centro significante do mundo, Tillich nos permite analisar a arte considerando as implicações da virada filosófica que se impõe com a filosofia de Nietzsche, em sua declaração da morte de Deus. Se a nietzschiana morte de Deus resulta no que Heidegger chamou de fim da metafísica, os desdobramentos dessas ideias, quando visíveis na literatura do século XX, em obras como a de Pessoa, podem nos apontar a literatura modernista como uma arte que se edifica no desespero humano frente à vacuidade de Deus? Se essa literatura se alimenta liricamente da angústia e manifesta a sua coragem na medida em que se assume desesperada, como repensar a relação entre religião e arte?

Com o título: Ontologia da angústia e coragem em Paul Tillich, a proposta de Henrique Nilo da Silva para o GT6 Paul Tillich, constitui-se em uma breve análise teórica-bibliográfica da ontologia da angústia e coragem que Paul Tillich desenvolveu em sua obra A Coragem de Ser (1952). Em diálogo interdisciplinar com a Tiefenpsychologie e psicanálise, investiga a situação existencial humana. Para apresentar a ontologia tillichiana, o autor utiliza três de suas preleções nas conferências pronunciadas na Yale University, organizadas no texto de 1952: Ser e 
Coragem; Ser, Não-Ser e Angústia; e Angústia Patológica, Vitalidade e Coragem. Em cada sessão apresenta-se o pensamento do autor em diálogo com textos de pesquisadores e estudiosos da religião. Primeiramente, mostra-se o percurso filosófico que o autor faz para chegar em seu conceito de coragem como "autoafirmação" apesar da finitude, alienação e neuroses. Depois, apresenta-se o esforço da ontologia tillichiana de compreender as principais questões existenciais do homem moderno e contemporâneo. Por fim, analisa-se o estado de confusão da teoria psicoterapêutica da angústia que não diferencia a angústia existencial da patológica. Destarte, ressaltando que a análise ontológica é um material para a psicologia formular uma teoria consistente e prática eficiente. Consequentemente, destaca-se a contribuição da ontologia da angústia e coragem tillichiana para a psicologia e os estudos de religião.

Os dois últimos artigos foram colocados na seção livre. O primeiro artigo é um texto importante sobre a filosofia da religião, que remete parcialmente ao pensamento de Tillich. Já foi publicado anteriormente, mas está sendo novamente disponibilizado para os leitores, com a autorização do autor. Com o título: A Contribuição da Filosofia da Religião para as Ciências da Religião: Impressões Gerais, o texto de Luís H. Dreher pretende ser mais um contributo à discussão contínua sobre as relações entre filosofia, filosofia da religião, teologia e a(s) ciência(s) da religião em sentido estrito. Busca-se, a partir de uma discussão contextual restrita ao ambiente brasileiro, tecer impressões gerais a partir de uma impostação propositalmente polêmica, que, porém, quer servir a considerações teóricas mais qualificadas que algumas atualmente prevalentes, e menos caracterizadas por estratégias defensivas, não raro até corporativas, pois motivadas pela urgência da sobrevivência política, institucional e acadêmica. No arcabouço dessa discussão maior, retoma-se o debate em torno da suposta "obsolescência" da fenomenologia da religião, caso típico e exemplar a requerer atenção filosófica-reflexiva; e em torno da pertença possível da filosofia da religião e da teologia à(s) ciência(s) da religião enquanto campo de estudos maleável - conquanto não tolerante a frouxidões quanto a teoria ou objeto -- e avesso a reducionismos metodológicos, sobretudo, mas não só, aqueles provenientes das ciências sociais. Em tudo isso o objetivo é endossar, mais uma vez, a complexidade do estudo da religião, evitando simplificações muitas 
vezes típicas de estudos empíricos e descritivos, cuja riqueza é muitas vezes apenas aparente, já que afinal o leigo pode sempre se perguntar: "Em todo esse caos, trata-se ainda de estudo da religião, este objeto específico prima facie reclamado por esta(s) ciência(s)?"

$\mathrm{O}$ artigo de Karlayne Maria de Moraes e Alex da Silva Mendes: A origem judaico-cristã do paradigma da governamentalidade e sua pertinência para uma análise do neoliberalismo atual, entra na revista por tematizar de certo modo a relação entre religião e cultura. O texto versa sobre a noção de governamentalidade proposta por Foucault e a pertinência desse conceito como "pedra de toque" para a realização de uma boa análise e compreensão da realidade atual. Num primeiro momento, a pesquisa se volta para a aula do dia oito de fevereiro de 1978, ministrada por Foucault, no Collège de France, em que o mesmo afirma que a origem de uma das mais eficazes estratégias de governo dos homens remonta a um paradigma judaico-cristão, a do pastor que conduz as suas ovelhas. Em seguida, buscar-se-á apresentar como o mesmo paradigma, base da governamentalidade de outrora, permanece vigente na realidade atual, ainda que com a utilização de outros instrumentais, porém com as mesmas finalidades de dirigir as consciências e as condutas à uma assimilação da ordem neoliberal cada vez mais incisiva. Objetiva-se, portanto, por meio desse artigo compreender qual é o paradigma base da noção de governamentalidade apresentada por Foucault e como esse mesmo paradigma mostra-se ainda hoje atuante e eficaz, no contexto hodierno, exercendo seu poder e vigilância sobre a conduta dos sujeitos que respondem de modo passivo.

A revista contém também uma resenha, obra de Viviane de Sousa Rocha. Ela contempla uma obra clássica do nosso autor de referência, Paul Tillich: A dinâmica da fé.

Desejamos a todas e a todos uma ótima leitura desse número excepcional da nossa revista. 
Vitor Chaves de Souza (Coeditor) 